\title{
Phenotype of mental health women presented with widespread pain
}

\author{
Talar Ahmad Merza Mohammad ${ }^{1}$, Marwan Salih Mohammad Al-Nimer ${ }^{2}$
}

\begin{abstract}
1 Department of Pharmacology and Toxicology, College of Pharmacy, Hawler Medical University
2 Department of Pharmacology and Toxicology, College of Pharmacy, Hawler Medical University

Corresponding author: Talar Ahmad Merza Mohammad, talar_ahmerza@yahoo.com
\end{abstract}

\section{ABSTRACT}

Background and Objective: Pain is one symptom that disturbs a patient's mental state, leading to a wide variety of symptoms like insomnia, fatigue, and emotional liability. This study aimed to identify the phenotype of patients complaining of a widespread of pain, considering the characteristic features and the associated mental symptoms.

Methods: This study was done in the Department of Pharmacology and Toxicology, College of Pharmacy, Hawler Medical University in 2019. A total number of 90 women were grouped into Group I ( $\mathrm{n}=20$, healthy subjects) and Group II ( $\mathrm{n}=70$, patients with widespread pain). Characteristic features, anthropometric measurements, blood pressure, the number of tender points (TPs), and the scores of fatigue, insomnia, and depression were determined.

Results: There are non-significant differences between Group I and II in the demographic characteristics, anthropometric measurements, and blood pressure level. The number of tender points and the scores of the fatigue, insomnia, and depression are significantly higher in Group II compared with Group I. Significant bivariate correlations were observed between the number of TPs with waist-to-height ratio $(r=-0.240, p=0.045)$ and fatigue $(r=0.275, p=$ 0.021). Fatigue symptom correlated with body mass index $(\mathrm{BMI})(\mathrm{r}=-0.380, \mathrm{p}=0.001)$ and WHeR $(r=-0.305, p=0.010)$, while the depressive symptom correlated with age $(r=0.232$, $\mathrm{p}=0.05)$, body mass index $(\mathrm{r}=-0.266, \mathrm{p}=0.026)$, and Waist-to-height ratio $(\mathrm{r}=-0.401, \mathrm{p}=0.001)$.

Conclusions: Low built women with fatigue is the phenotype of women presented with widespread pain. A triad of fatigue, insomnia, and depression are significant symptoms associated with pain and correlated with the women's built.

Keywords: Phenotype, pain, mental health, fatigue, depression 


\section{Proceeding of the $2^{\text {nd }}$ Scientific Conference on Women's Health \\ 2-3 September 2020 - Hawler Medical University}

\section{INTRODUCTION}

Pain is a commonly conspicuous somatic involvement that mirrors an individual's fear of physical or existential integrity threat. ${ }^{1}$ Individual reporting extensive pain tend to have a smaller total lean mass and more total fat mass than those who do not report pain. ${ }^{2}$ Significant evidence indicates that the connection between chronic pain and obesity is multifactorial and complex and may contain a range of systemic inflammation, an overload of skeletal muscles, and autonomic dysfunction. ${ }^{3}$ Furthermore, psychological and social issues might not be overlooked as the cause of the problem. ${ }^{4} \mathrm{~A}$ meta-analysis confirmed that overweight and obesity are linked with the possibility of backache in the lower part of both males and females. Researchers have displayed a relationship between chronic pelvic pain in females and mood disturbances. ${ }^{5}$ Also, women's mental health is closely connected to obesity and overweight compared to men's health. ${ }^{6}$ Concerning the connection between depression and body mass index (BMI), research attested that being obese and underweight at baseline is considerably linked with the upcoming occurrence of depression amongst females. ${ }^{6}$ Evidence indicates that the severity of depression increases with the availability of cardiac risk factors waist circumference and BMI. ${ }^{7}$ Variables such as percentage of body fat; height $(\mathrm{cm})$; sleeplessness; hand grip strength; anxiety and depression symptom scores were varied considerably amongst females with or without day-to-day muscle / joint pain. ${ }^{8}$ In overweight and obese women, each one-unit extend in BMI was connected with 0.11 increased detected fatigue. ${ }^{9}$ Individuals who are obese, stimulating a cycle of extreme fatigue, decreased activity, and more bodyweight increment of body weight.10There are robust connections between central obesity and fatigue. Kang and his colleagues attested that in women patients over 65 years of age, cognition tends to lessen due to reduced grip strength haste of walking gets slower, more severe depression. As age rises. ${ }^{11}$ Therefore, we hypothesized that the low built women with fatigue are the phenotype of women presented with widespread pain. This study aimed to characterize the phenotype of women presented with wide spread skeletomuscular pain associated with mental symptoms in terms of fatigue, insomnia, and depression. 


\section{Proceeding of the $2^{\text {nd }}$ Scientific Conference on Women's Health \\ 2-3 September 2020 - Hawler Medical University}

\section{PATIENTS AND METHODS}

\section{Setting and Ethical considerations}

This study was implemented at Hawler Medical University, College of Pharmacy in the Department of Pharmacology and Toxicology, from January to the end of January 2019. The Institutional Scientific Committee approved the study at Hawler Medical University. Regarding patient privacy and medical ethics, all participants were informed that their data would be used to achieve the study goals, and each participant signed a consent form. A total number of 90 women sub-grouped into Group I ( $n=20$, healthy subjects) and Group II ( $n=70$, patients with widespread pain).

\section{Participants, criteria of inclusion, exclusion, and recruitment}

The patients were recruited from the Rizgary Teaching Hospital in Erbil and the Private and the Public Medical Clinics in Erbil. The subjects who seemed to be in good health from the people working in the Clinical Centers and the patients attending the clinics were enrolled.

The inclusion criteria are women presenting with widespread pain greater than or equal 35 and less than 50 years' old. The exclusion criteria are men, pregnant women.

A properly plan questionnaire was created, containing the demographic traits related to the epidemiology and the nature of pain utilized in this study. The waist circumference $(\mathrm{cm})$ was measured by measurement tape with an unclothed abdomen at the midpoint between the lower costal margin and the iliac crest's top, with the participants standing position. Waist to height ratio (WHtR) was calculated using the following formula:

$\mathrm{WHtR}=\frac{W C(\mathrm{~cm})}{\operatorname{height}(\mathrm{cm})}$

According to the World Health Organization (WHO), the WHeR was categorized as

Extreme slim (<0.34), Healthy women (0.42-0.48), overweight (0.49-0.35), and very overweight (0.54-0.57) and obese $(>0.58)$. The height $(\mathrm{m})$ and the body weight $(\mathrm{kg})$ had been measured. The body mass index (BMI) was calculated with the aid of the usage of the following formula:

$\operatorname{BMI}\left(\mathrm{kg} / \mathrm{m}^{2}\right)=($ weight $(\mathrm{kg})) /\left(\right.$ height $\left.^{2}(\mathrm{~m})\right)$

Blood pressure was measured in the sitting position and recorded using a mercuric digital sphygmomanometer. The mean value of at least three readings (systolic and diastolic blood pressure) over five minutes was considered in this study. The number of tender points was 


\section{Proceeding of the $2^{\text {nd }}$ Scientific Conference on Women's Health 2-3 September 2020 - Hawler Medical University}

estimated; a deep pressure was applied by the thumb. Pain intensity was objectively assessed using a visual analog scale. The Insomnia Severity Index (ISI) was utilized to evaluate insomnia, which is a seven-element questionnaire and items scored on a five-point scale with zero $=$ no problem and $4=$ severe. Insomnia is defined as the sum of ISI $\geq 10$ points. ${ }^{12}$

Fatigue symptoms were evaluated using the Fatigue severity scale (FSS), a nine-element questionnaire, and items scored on a 7-point scale with $1=$ strongly disagree, and $7=$ strongly agree. The mean value for all grades was determined. ${ }^{13}$ Signs, and symptoms associated with depression-relates were evaluated by utilizing the Hamilton's Depression Rating Scale (HDRS-21). ${ }^{14}$ A score of less than seven indicates the absence of depression, grades of 7 to 17 point out mild depression; from 18 to 24 moderate; and $\geq 25$ specify severe depression.

\section{Statistical analysis}

All data were coded, entered, and analyzed using Excel software 2007 and SPSS version 20. The data expressed as number, percentage, and mean \pm SD. The data analysis and the calculation of the probability (p) values were performed using the following tests: two-tailed independent two-sample t-test for continuous, Chi-squared test for categorized data, simple correlation (Pearson) and, multivariant regression analysis test was done. The probability value of $\leq 0.05$ regarded statistically significant.

\section{RESULTS}

The result shows that the mean \pm SD of age Group II patients did not significantly differ from Group I subjects' corresponding values. The majority of the participants were housewives (55\% of Group I versus $54.3 \%$ of the Group II). Most of the patients were married (75\% of Group I versus $70 \%$ of Group II). Current results showed that the highest percentage of the patients was non-smokers (75\% of the Group I versus $81.42 \%$ of the Group II). There is a non-significant difference between Groups I and II in the education level. The minority of the participants were living in the rural area (10\% of the Group I versus $21.42 \%$ of the Group II). Family history of mental diseases were non-significantly higher in the Group II compared with Group I. At the time of inclusion of the study, Group II patients had a prior history of attending the psychiatric clinics by $21.4 \%$. The majority of patients using analgesics (Table 1). A non-significant variation was reported between Group I and Group II in the anthropometric measurements, involving the body mass index and waist to height ratio. 


\section{Proceeding of the $2{ }^{\text {nd }}$ Scientific Conference on Women's Health \\ 2-3 September 2020 - Hawler Medical University}

There is a non-significant difference in the systolic and diastolic blood pressures in Group II compared with Group I.

The mean \pm SD of the duration of the widespread pain was $19.4 \pm 2.6$ weeks. Significant high scores of tender points, fatigue severity scale, insomnia (assessed by insomnia severity index), depression (that assessed by the Hamilton's depression scale) detected in Group II, which accounted for 2.84, 1.95, 3.29, and 2.42 folds correspondingly (Table 2).

Significant bivariate correlations were observed between the number of TPs with WHeR ( $r=-$ $0.240, \mathrm{p}=0.045)$, and fatigue symptom $(\mathrm{r}=0.275, \mathrm{p}=0.021)$ (Table 3$)$. Fatigue symptom significantly correlated with BMI $(\mathrm{r}=-0.380, \mathrm{p}=0.001)$ and WHeR $(\mathrm{r}=-0.305, \mathrm{p}=0.010)$ while the depression score significantly correlated with age $(\mathrm{r}=0.232, \mathrm{p}=0.05)$; BMI $(\mathrm{r}=-0.266$, $\mathrm{p}=0.026)$; and WHeR ( $\mathrm{r}=-0.401, \mathrm{p}=0.001)$ (Table 3).

Figure 1 shows the multivariable regression analysis results between the fatigue severity scale (dependent variable) with the number of TPs, BMI, and WHeR (as independent variables), which reached a significant level with a prediction value of $22.0 \%$.

Multivariable regression analysis exhibited that there was a significant correlation between the Hamilton's Depression rating scale (dependent variable) with age, BMI, and WHeR (as independent variables) with a prediction value of $20.6 \%$ (Figure 2).

\section{DISCUSSION}

This study indicates that low built women with fatigue are the phenotype of women presented with widespread pain. A triad of fatigue, insomnia, and depression are significant symptoms that are connected with pain and correlated with the built of the women. Fatigue is usually linked with chronic pain; in rheumatic diseases, both the presence and severity of these symptoms are closely related. ${ }^{15}$ A plurality of osteoarthritis fatigue study concludes that males have lower levels of fatigue when compared to females. ${ }^{16} \mathrm{~A}$ study confirmed that one of the primary symptoms of fibromyalgia is fatigue. It appears that both the low quality of sleep and catastrophizing affect fatigue levels. ${ }^{17}$ It suggested that cellular aging in women with fibromyalgia, maybe distinctively linked with sleep quality and pain thresholds. ${ }^{18}$ In women with widespread chronic pain, the higher body mass index is negatively associated with the quality of life, functional aptitude, and socioeconomic. 
Proceeding of the $2^{\text {nd }}$ Scientific Conference on Women's Health

2-3 September 2020 - Hawler Medical University

Table 1: Characteristics of the participants enrolled in the study

\begin{tabular}{|c|c|c|c|}
\hline Variables & $\begin{array}{l}\text { Healthy } \\
\mathbf{N = = 2 0}\end{array}$ & $\begin{array}{l}\text { Patients } \\
(\mathrm{n}=70)\end{array}$ & $\mathrm{p}$-value \\
\hline Age & $44.2 \pm 7.3$ & $42.3 \pm 7.3$ & 0.308 \\
\hline \multicolumn{4}{|l|}{ Smoking } \\
\hline Current & $04(20)$ & $9(12.9)$ & 0.423 \\
\hline Ex-smoker & $01(5)$ & $4(5.7)$ & \\
\hline \multicolumn{4}{|l|}{ Occupation } \\
\hline Employee & $7(35)$ & $28(40)$ & 0.767 \\
\hline Housewives & $11(55)$ & $38(54.3)$ & \\
\hline Others & $2(10)$ & $04(5.7)$ & \\
\hline \multicolumn{4}{|l|}{ Education } \\
\hline University & $05(25)$ & $19(27.1)$ & 0.633 \\
\hline Secondary & $07(35)$ & $25(35.7)$ & \\
\hline Primary & $06(30)$ & $20(28.6)$ & \\
\hline Illiterate & $02(10)$ & $06(8.6)$ & \\
\hline \multicolumn{4}{|l|}{ Marital status } \\
\hline Single & $03(15)$ & $7(10)$ & 0.503 \\
\hline Married & $15(75)$ & $49(70)$ & \\
\hline Divorced & $0(0)$ & $4(5.7)$ & \\
\hline Widow & $02(10)$ & $10(14.3)$ & \\
\hline \multicolumn{4}{|l|}{ Residency } \\
\hline Rural & $2(10)$ & $15(21.42)$ & 0.249 \\
\hline Urban & $18(90)$ & $55(78.57)$ & \\
\hline $\begin{array}{l}\text { Family history of mental } \\
\text { diseases }\end{array}$ & $13(65)$ & $53(75.7)$ & 0.339 \\
\hline $\begin{array}{l}\text { Attending psychiatric } \\
\text { clinics }\end{array}$ & $2(10)$ & $15(21.42)$ & 0.249 \\
\hline Using analgesics & $14(70)$ & $55(78.57)$ & 0.424 \\
\hline Body mass index $\left(\mathrm{kg} / \mathrm{m}^{2}\right)$ & $25.2 \pm 1.2$ & $25.7 \pm 2.7$ & 0.424 \\
\hline Waist/Height ratio & $0.520 \pm 0.023$ & $0.525 \pm 0.033$ & 0.528 \\
\hline $\mathrm{SBP}(\mathrm{mmHg})$ & $132.4 \pm 7.3$ & $134.7 \pm 13.1$ & 0.455 \\
\hline $\mathrm{DBP}(\mathrm{mmHg})$ & $82.9 \pm 3.3$ & $80.2 \pm 8.0$ & 0.145 \\
\hline
\end{tabular}

The results are expressed as mean \pm SD. P-value was calculated by using two-tailed independent two-sample ttest for continuous data and Chi-squared test for categorized data 


\section{Proceeding of the $2^{\text {nd }}$ Scientific Conference on Women's Health 2-3 September 2020 - Hawler Medical University}

Table 2: Assessment of the mental health of women presented with widespread pain

\begin{tabular}{llll}
\hline Variables & $\begin{array}{l}\text { Healthy } \\
\text { subjects } \\
(\mathrm{n}=20)\end{array}$ & $\begin{array}{l}\text { Patients } \\
(\mathrm{n}=70)\end{array}$ & p-value \\
& $5.0 \pm 1.5$ & $14.2 \pm 1.7$ & $<0.001$ \\
\hline Tender points (No.) & & $19.4 \pm 2.6$ & \\
Duration of pain (weeks) & $2.25 \pm 0.21$ & $4.39 \pm 0.32$ & $<0.001$ \\
Fatigue severity scale & $5.6 \pm 1.39$ & $18.46 \pm 2.11$ & $<0.001$ \\
Insomnia severity index & $10.9 \pm 2.92$ & $26.39 \pm 5.45$ & $<0.001$ \\
Hamilton's depression rating scale & &
\end{tabular}

The results are expressed as mean \pm SD. P-value was calculated by using two-tailed independent two-sample $\mathrm{t}$ test for continuous data.

Table 3: Correlation between the mental health of women presented with widespread pain with the with the physical characteristics

\begin{tabular}{llllll}
\hline Variables & Duration & TP & FSS & Insomnia & $\begin{array}{l}\text { Hamilton's } \\
\text { depression } \\
\text { rating scale }\end{array}$ \\
\hline Age & & & & & 0.232 \\
Body mass index $\left(\mathrm{kg} / \mathrm{m}^{2}\right)$ & -0.085 & -0.151 & -0.380 & 0.044 & -0.266 \\
& $(0.482)$ & $(0.211)$ & $(0.001)$ & $(0.718)$ & $(0.026)$ \\
Waist-to-height ratio & -0.033 & -0.240 & -0.305 & 0.062 & -0.401 \\
& $(0.789)$ & 0.045 & $(0.010)$ & $(0.609)$ & $(0.001)$ \\
Systolic blood pressure & -0.114 & 0.167 & 0.013 & 0.032 & 0.179 \\
(mmHg) & $(0.347)$ & $(0.167)$ & $(0.914)$ & $(0.789)$ & $(0.139)$ \\
Diastolic blood pressure & -0.132 & 0.053 & 0.005 & -0.138 & -0.141 \\
(mmHg) & $(0.277)$ & $(0.664)$ & $(0.969)$ & $(0.256)$ & $(0.244)$ \\
Duration & & -0.185 & -0.051 & 0.122 & 0.003 \\
Of pain (week) & & $(0.125)$ & $(0.676)$ & $(0.313)$ & $(0.979)$ \\
Tender points (number) & & & 0.275 & 0.197 & 0.077 \\
& & & $(0.021)$ & $(0.102)$ & $(0.528)$ \\
Fatigue severity scale & & & & -0.075 & 0.091 \\
& & & & $(0.538)$ & $(0.455)$ \\
Insomnia severity index & & & & -0.099 \\
& & & & $(0.417)$ \\
\hline
\end{tabular}

The results are expressed as correlation factor (probability). Correlation factor (Pearson) was calculated by using bivariate correlation test. 


\section{Proceeding of the $2^{\text {nd }}$ Scientific Conference on Women's Health \\ 2-3 September 2020 - Hawler Medical University}

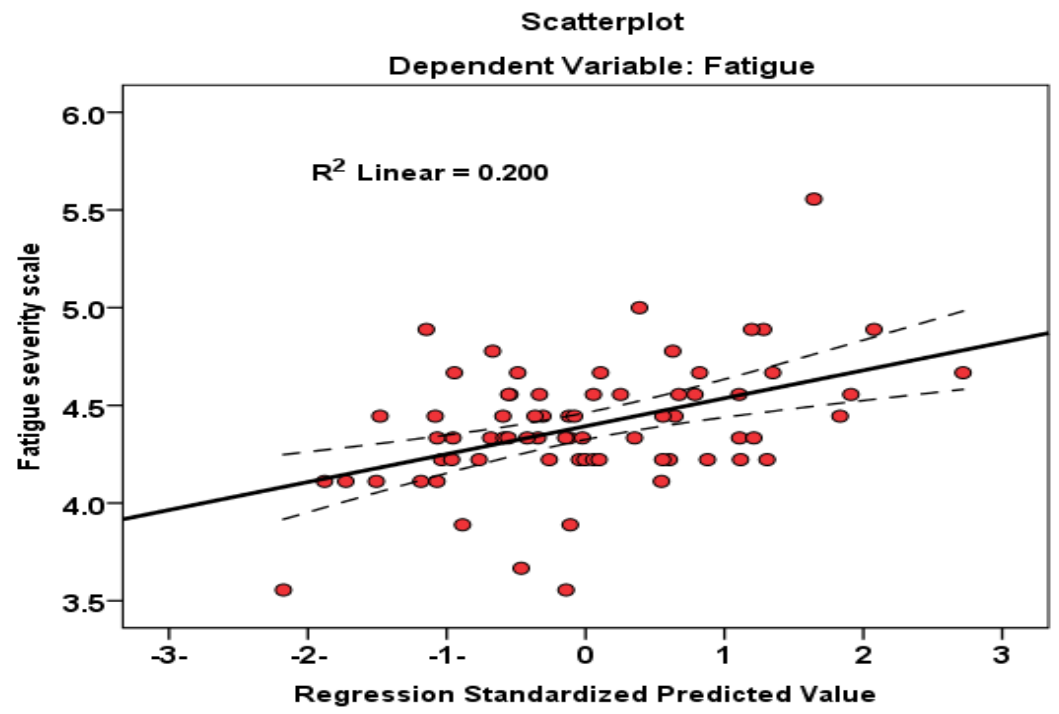

Figure 1- Multivariable regression analysis of correlation between the fatigue severity scale (dependent variable) with the number of tender points, body mass index, and waist-to-height ratio (as independent variables). $\left(\mathrm{R}^{2}=0.220, \mathrm{R}=0.447, \mathrm{~F}=5.494, \mathrm{p}=0.002\right.$, predictive value $=22 \%)$. Fatigue severity scale $=5.27+(-0.035 \times \mathrm{BMI})+(-0.998 \mathrm{x}$ waist-to-height ratio $)+$ (0.039xnumber of tender points).

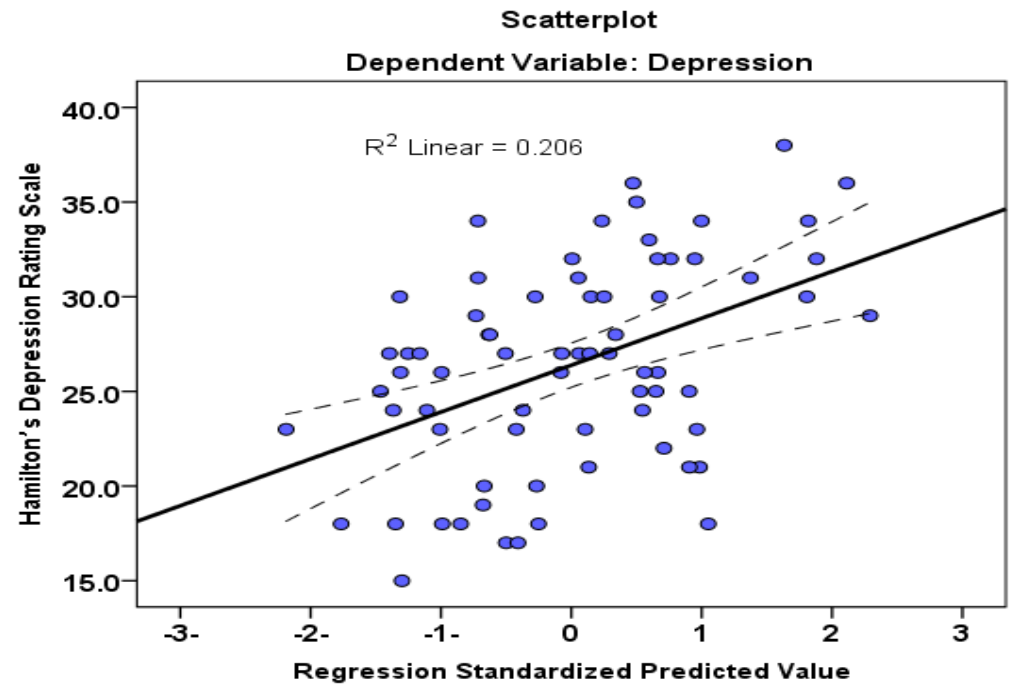

Figure 2- Multivariable regression analysis of correlation between the Hamilton's Depression rating scale (dependent variable) with the age, body mass index, and waist-toheight ratio (as independent variables). $\left(\mathrm{R}^{2}=0.206, \mathrm{R}-0.454, \mathrm{~F}=5.705, \mathrm{p}=0.002\right.$, predictive value $=20.6 \%)$. Depression rating scale $=54.4+(-0.160 \times \mathrm{BMI})+(-57.7 \mathrm{x}$ waist-to-height ratio $)+(0.150$ xage $)$. 


\section{Proceeding of the $2^{\text {nd }}$ Scientific Conference on Women's Health 2-3 September 2020 - Hawler Medical University}

A study confirmed that the score of both FSS, ISI, and Hamilton's scale for depression (HSD) was significantly higher in fibromyalgia patients than the corresponding value in healthy subjects. ${ }^{19}$ Our study confirms a significant bivariate correlation between the fatigue severity with the number of tender points, body mass index, and waist-to-height ratio. ${ }^{20,21}$ Factors observed to affect the body mass index and central obesity are gender and ethnicity, and socioeconomic factors. Several studies showed that increment of body mass index resulted in a significant increase of tender points number and a considerable reduction of life domains. $^{22,23}$ Body mass index was positively correlated and significantly with tender point count, depression in women with fibromyalgia. ${ }^{24}$ However, another study confirmed a nonsignificant connection between the number of tender points, fatigue, body mass index, and patients with the higher percentage of fat mass having more sleep impairment. ${ }^{25} \mathrm{~A}$ study attested that occurrence of depression in women above or under the age of 55 was elevated, but the gender difference was statistically non-significant after the age of $55^{26}$, and ${ }^{27}$ suggested that the prevalence of depression rapidly decrease in menopausal women. This study shows a positive and significant correlation between Hamilton's Depression rating scale and BMI in agreement with ${ }^{28}$ showed a strong association between mental disorder and being obese or overweight amongst females compared to males. ${ }^{29}$

\section{CONCLUSIONS}

Low built women with fatigue is the phenotype of women displayed with widespread pain. A set of three of fatigue, insomnia, and depression are significant symptoms connected with pain and correlated with the women's built.

Conflict of Interest: There are no conflicts of interest

\section{REFERENCES}

1.Cohen M, Quintner J, van Rysewyk S. Reconsidering the International Association for the Study of Pain definition of pain. Pain Rep 2018;3(2):e634. doi: 10.1097/PR9.0000000000000634

2. Yoo JJ, Cho NH, Lim SH, Kim HAJA. Relationships between body mass index, fat mass, muscle mass, and musculoskeletal pain in community residents. Arthritis Rheum 2014;66(12): 3511-20. DOI: 10.1002/art.38861 


\section{Proceeding of the $2^{\text {nd }}$ Scientific Conference on Women's Health 2-3 September 2020 - Hawler Medical University}

3.Janke EA, Fritz M, Hopkins C, Haltzman B, Sautter JM, Ramirez ML. A randomized clinical trial of an integrated behavioral self-management intervention Simultaneously Targeting Obesity and Pain: the STOP trial. BMC Public Health 2014;14(1):621.DOI: https://www.biomedcentral.com/1471-2458/14/621

4.Zdziarski LA, Wasser JG, Vincent HK. Chronic pain management in the obese patient: a focused review of key challenges and potential exercise solutions.J Pain Res 2015;8:63-77. DOI: $10.2147 / J P R . S 55360$

5.Ayorinde AA, Bhattacharya S, Druce KL, Jones GT, Macfarlane GJ. Chronic pelvic pain in women of reproductive and post-reproductive age: a population-based study. Eur J Pain 2017:21(3): 445-55.DOI: https://doi.org/10.1002/ejp.938

6.Martin-Rodriguez E, Guillen-Grima F, Aubá E, Marti A, Brugos-Larumbe A. Relationship between body mass index and depression in women: a 7-year prospective cohort study. The APNA study. Eur Psychiatry 2016;32:55-60.

DOI: https://doi.org/10.1016/j.eurpsy.2015.11.003

7.Bhardwaj M, Price J, Landry M, Harvey P, Hensel JM. Prevention. Association Between severity of depression and cardiac risk factors among women referred to a cardiac rehabilitation and prevention clinic. J Cardiopulm Rehabil Prev 2018;38(5):291-6.DOI: 10.1097/HCR.0000000000000311

8.Terauchi M, Odai T, Hirose A, Kato K, Akiyoshi M, Miyasaka N et al. Muscle and joint pains in middle-aged women are associated with insomnia and low grip strength: a crosssectional study. J Psychosom Obstet Gynaecol 2018:1-7.

DOI: 10.1080/0167482X.2018.1530211

9.Martinez-Amezcua P, Simonsick EM, Wanigatunga AA, Urbanek JK, Chiles Shaffer N, Ferrucci L, et al. Association Between Adiposity and Perceived Physical Fatigability in Midto Late Life. Int J Obes 2019; 27(7): 1177-83.

DOI: https://doi.org/10.1002/oby.22500

10.Cooper R, Huang L, Hardy R, Crainiceanu A, Harris T, Schrack JA, et al. Obesity history and daily patterns of physical activity at age 60-64 years: findings from the MRC National Survey of Health and Development. J Gerontol A Biol Sci Med Sci 2017;72(10):142430.DOI: https://doi.org/10.1093/gerona/glw331 https://doi.org/10.1080/01635581.2017.1367938

11.Kang JY, Kim CH, Sung EJ, Shin HC, Shin WJ, Jung KH. The association between frailty and cognition in elderly women. J Korean Med Sci 2016;37(3):164. DOI: $10.4082 / \mathrm{kjfm} .2016 .37 .3 .164$ 


\section{Proceeding of the $2^{\text {nd }}$ Scientific Conference on Women's Health 2-3 September 2020 - Hawler Medical University}

12.Kim J, Cho SJ, Kim WJ, Yang KI, Yun CH, Chu MK, et al. insomnia in tension-type headache: a population-based study. J Headache Pain 2017;18(1):95. DOI 10.1186/s10194017-0805-3

13.Learmonth Y, Dlugonski D, Pilutti L, Sandroff B, Klaren R, Motl RW. Psychometric properties of the fatigue severity scale and the modified fatigue impact scale. J Neurol Sci2013;331(1-2):102-7.

DOI: https://doi.org/10.1016/j.jns.2013.05.023

14.Hamilton M. The Hamilton Depression Scale-accelerator or break on antidepressant drug discovery. Am J Psychiatry 1960;23:56-62.

15.Katz P, Margaretten M, Trupin L, Schmajuk G, Yazdany J, Yelin EJAc, et al. Role of sleep disturbance, depression, obesity, and physical inactivity in fatigue in rheumatoid arthritis. Arthritis Care Res 2016;68(1):81-90.DOI: https://doi.org/10.1002/acr.22577

16.Hawker GA, Gignac MA, Badley E, Davis AM, French MR, Li Y, et al. A longitudinal study to explain the pain-depression link in older adults with osteoarthritis. Arthritis Care Res 2011;63 (10):1382-90.DOI: https://doi.org/10.1002/acr.20298

17.Dorado K, Lazaridou A, Franceschelli O, Protsenko K, Napadow V, Edwards R. (310) The association between catastrophizing, fatigue, and sleep quality among patients with fibromyalgia. J Pain 2017;18(4):S53. DOI: https://doi.org/10.1016/j.jpain.2017.02.203 18.Iacob E, Hassett A, Neikrug A, Okifuji A. (314) Sleep and pain sensitivity and its relationship to cellular aging in women with fibromyalgia. J Pain 2017;18(4):S53-S4. DOI: https://doi.org/10.1016/j.jpain.2017.02.207

19.Al-Nimer MS, Mohammad TA, Maroof A. Dysfunction of anterior pituitary gland in women patients with recent fibromyalgia: A cross-sectional observational study. Electron J Gen Med 2018;15(4).DOI: https://doi.org/10.29333/ejgm/90278

20.Andrea SB, Hooker ER, Messer LC, Tandy T, Boone-Heinonen J. Does the association between early life growth and later obesity differ by race/ethnicity or socioeconomic status? A systematic review. Ann Epidemiol 2017;27(9):583-92. DOI: https://doi.org/10.1016/j.annepidem.2017.08.019

21.Petravičienė I, Gražulevičienė R, Andrušaitytė S, Dėdelè A. Impact of the social and natural environment on preschool-age children weight. Int $\mathbf{J}$ Environ Res Public Health 2018;15(3):449. DOI:10.3390/ijerph15030449

22.Shaker RH, Soliman AF, Elbrashy AE-WS, Fouda AI, Attia SM. Women with Fibromyalgia: Association of Body Mass Index with Socioeconomic Status, Disease Severity, Functional Disability and Quality of Life. J Egypt Public Health Assoc 2017;35(3). 


\section{Proceeding of the $2^{\text {nd }}$ Scientific Conference on Women's Health 2-3 September 2020 - Hawler Medical University}

23.Timmerman GM, Calfa NA, Stuifbergen AK.Correlates of body mass index in women with fibromyalgia. Orthop Nurs 2013;32(2):113. DOI: 10.1097/NOR.0b013e3182879c08

24. Koçyiğit BF, Okyay RA. The relationship between body mass index and pain, disease activity, depression and anxiety in women with fibromyalgia. PeerJ Prepr 2018;6:e4917.DOI: https://doi.org/10.7717/peerj.4917

25.Correa-Rodríguez M, Mansouri-Yachou JE, Casas-Barragán A, Molina F, Rueda-Medina B, Aguilar-Ferrándiz ME. The Association of Body Mass Index and Body Composition with Pain, Disease Activity, Fatigue, Sleep and Anxiety in Women with Fibromyalgia. Nutrients $2019 ; 11(5): 1193$. DOI:10.3390/nu11051193

26.Faravelli C, Scarpato MA, Castellini G, Sauro CL. Gender differences in depression and anxiety: the role of age. Psychiatry Res 2013;210(3):1301-3. DOI: https://doi.org/10.1016/j.psychres.2013.09.027

27.Patten SB, Williams JV, Lavorato DH, Wang JL, Bulloch AG, Sajobi T, et al. The association between major depression prevalence and sex becomes weaker with age. Soc Psychiatry Psychiatr Epidemiol 2016;51(2):203-10.

28.Husky MM, Mazure CM, Ruffault A, Flahault C, Kovess-Masfety V. Differential associations between excess body weight and psychiatric disorders in men and women. Int $\mathbf{J}$ Womens Health 2018;27(2):183-90.

DOI: https://doi.org/10.1089/jwh.2016.6248

29.Arroyo KJ, Ramos-Torres G, Mezones-Holguin E, Blümel JE, Barón G, Bencosme A, et al. Association between waist-to-height ratio and anxiety in middle-aged women: a secondary analysis of a cross-sectional multicenter Latin American study. Menopause 2018;25(8):90411. DOI: 10.1097/GME.0000000000001089 